\title{
Glutamate Blocks Serotonergic Phase Advances of the Mammalian Circadian Pacemaker through AMPA and NMDA Receptors
}

\author{
Rebecca A. Prosser \\ Department of Biochemistry and Cellular and Molecular Biology, University of Tennessee, Knoxville, Tennessee 37996
}

The phase of the mammalian circadian pacemaker, located in the suprachiasmatic nucleus (SCN), is modulated by a variety of stimuli, most notably the environmental light cycle. Light information is perceived by the circadian pacemaker through glutamate that is released from retinal ganglion cell terminals in the SCN. Other prominent modulatory inputs to the SCN include a serotonergic projection from the raphe nuclei and a neuropeptide $Y$ (NPY) input from the intergeniculate leaflet. Light and glutamate phase-shift the SCN pacemaker at night, whereas serotonin $(5-\mathrm{HT})$ and NPY primarily phase-shift the pacemaker during the day. In addition to directly phase-shifting the circadian pacemaker, SCN inputs have been shown to modulate the actions of one another. For example, 5-HT can inhibit the phase-shifting effects of light or glutamate applied to the SCN at night, and NPY and glutamate inhibit phase shifts of

The suprachiasmatic nucleus ( $\mathrm{SCN}$ ) contains the primary circadian clock in mammals (Moore, 1995). The SCN pacemaker generates sustained near-24 hr oscillations in vitro when maintained in culture in the absence of synchronizing stimuli (Shinohara et al., 1995; Yamazaki et al., 2000). Under normal conditions, however, SCN pacemaker phase is modulated by a variety of signals. These signals are generally divided into two categories: photic signals that modulate circadian phase when presented during the subjective night and nonphotic signals that modulate circadian phase when presented during the subjective day. The best characterized photic signal is light itself, which induces phase delays during the early night and phase advances during the late night (Takahashi and Zatz, 1982). These effects are mimicked by injecting glutamate or its agonists into the SCN (Mintz et al., 1999) or applied in vitro (Ding et al., 1994, 1997). Light and glutamate are thought to modulate the clock through activating NMDA and non-NMDA glutamate receptors, increasing intracellular $\mathrm{Ca}^{2+}$, and activating nitric oxide synthase (Ding et al., 1994, 1997, 1998; Hamada et al., 1999; Mintz et al., 1999). Glutamate and light also activate cAMP response elementbinding protein, increase c-fos levels, and increase levels of the circadian clock-associated gene products mPER1 and mPER2, any or all of which may be critical for photic phase shifts (Ding et al., 1997; Akiyama et al., 1999; Francois-Bellan et al., 1999; Obrietan et al., 1999; Field et al., 2000).

Nonphotic stimuli, conversely, phase-advance the SCN pace-

\footnotetext{
Received May 15, 2001; revised July 17, 2001; accepted July 23, 2001.

This research was supported by National Institutes of Health Grant MH53317.

Correspondence should be addressed to Dr. Rebecca A. Prosser, Department of Biochemistry and Cellular and Molecular Biology, M407 Walters Life Sciences Building, University of Tennessee, Knoxville, TN 37996. E-mail: rprosser@utk.edu. Copyright (C) 2001 Society for Neuroscience $0270-6474 / 01 / 217815-08 \$ 15.00 / 0$
}

one another. In this study, we explored the possibility that glutamate can modulate serotonergic phase shifts during the day. For these experiments, we applied various combinations of 5-HT agonists, glutamate agonists, and electrical stimulation of the optic chiasm to SCN brain slices to determine the effect of these treatments on the rhythm of spontaneous neuronal activity generated by the SCN circadian pacemaker. We found that glutamate agonists and optic chiasm stimulation inhibit serotonergic phase advances and that this inhibition involves both AMPA and NMDA receptors. This inhibition by glutamate may be indirect, because it is blocked by both tetrodotoxin and the $\mathrm{GABA}_{\mathrm{A}}$ antagonist, bicuculline.

Key words: suprachiasmatic; circadian; serotonin; glutamate; NMDA; AMPA; tetrodotoxin; DPAT; bicuculline; brain slice; rat

maker when applied during the subjective day and generally have smaller effects at night. These stimuli include behavioral activity (Mrosovsky, 1995), sleep deprivation (Antle and Mistlberger, 2000; Grossman et al., 2000), and application of neuropeptide Y (NPY) (Biello et al., 1994; Golombek et al., 1996), melatonin (Cassone et al., 1985; Gillette and McArthur, 1996), GABA (Smith et al., 1989; Biggs and Prosser, 1998), or serotonin (5-HT) agonists (Medanic and Gillette, 1992; Shibata et al., 1992b; Tominaga et al., 1992; Edgar et al., 1993; Prosser et al., 1993) to the SCN.

Recent investigations have demonstrated interactions between phase-shifting stimuli. Most notably, several nonphotic stimuli (e.g., wheel-running behavior, 5-HT agonists, and NPY) have been shown to inhibit light- and/or glutamate-induced phase shifts (Ralph and Mrosovsky, 1992; Pickard et al., 1996; Biello et al., 1997; Pickard and Rea, 1997a; Mistlberger and Antle, 1998; Weber et al., 1998; Yannielli and Harrington, 2000). Glutamate and light, in turn, can block NPY-induced phase shifts (Biello et al., 1997), and light inhibits activity-arousal-induced phase shifts (Mrosovsky, 1991; Biello and Mrosovsky, 1995; Antle and Mistlberger, 2000; Grossman et al., 2000). To further explore photic-nonphotic interactions, the experiments presented here focus on whether glutamate can inhibit serotonergic phase shifts in vitro. The results indicate that glutamate inhibits serotonergic phase advances through stimulating both AMPA and NMDA receptors, and this effect is mimicked by electrical stimulation of the optic chiasm. In addition, the inhibition by glutamate appears to be indirect, possibly involving GABA interneurons.

\section{MATERIALS AND METHODS}

Brain slice preparation. Coronal brain slices $(500 \mu \mathrm{m})$ containing the SCN were prepared during the daytime from adult, male Sprague Dawley rats housed in a $12 \mathrm{hr}$ light/dark cycle as reported previously (Prosser and 
Gillette, 1989; Prosser et al., 1993; Prosser, 1998b). Slices were maintained at the interface of a Hatton-style brain slice chamber (Hatton et al., 1980) in which they were perfused continuously with warm $\left(37^{\circ} \mathrm{C}\right)$, oxygenated $\left(95 \% \mathrm{O}_{2} / 5 \% \mathrm{CO}_{2}\right)$, glucose-bicarbonate-supplemented Earle's Balanced Salt Solution (EBSS; Sigma, St. Louis, MO), pH 7.4-7.5.

Single-unit recordings and data analysis. Single-unit recordings were obtained using methods described previously (Prosser et al., 1993; Prosser, 1998b). Briefly, the spontaneous activity of single SCN neurons was recorded using glass capillary microelectrodes filled with $3 \mathrm{M} \mathrm{NaCl}$. Each neuron was recorded for $5 \mathrm{~min}$, and the data was stored for later determination of firing rate using a DataWave system (DataWave Technologies, Longmont, CO). In general, four to seven cells were recorded during each hour. These firing rates were used then to calculate $2 \mathrm{hr}$ running averages, lagged by $1 \mathrm{hr}$, to obtain a measure of population neuronal activity. As in previous studies (Prosser et al., 1993; Prosser, 1998b), the time of peak neuronal activity was assessed visually by estimating, to the nearest quarter hour, the time of symmetrically highest activity.

Experimental treatments. All drugs used in phase-shifting experiments were bath-applied during the first day in vitro by stopping the perfusion and replacing the medium in the slice chamber with medium containing the test compound. At the end of the treatment period, the normal medium was reintroduced into the slice chamber, and perfusion was resumed. In most experiments, the treatment period lasted $1 \mathrm{hr}$, but in some experiments a 10 min application was used. In another group of experiments, the medium in the slice chamber was replaced three times with fresh medium containing the test compound(s) at 20 min intervals during the hour-long treatment. This method was initially used to test the blocking effects of glutamate after the $1 \mathrm{hr}$ bath application was found ineffective (see Table 1). The reasoning behind this was that the glutamate might undergo rapid degradation and/or sequestration during the static bath conditions (Yudkoff et al., 1994; Hertz et al., 1999). This method of drug application produced positive results with glutamate, but not NMDA or kainate (see Table 1). For blocking experiments, the bathing medium was first replaced with medium containing the blocking compound. After $15 \mathrm{~min}$ (or after $5 \mathrm{~min}$, if using the shorter, $10 \mathrm{~min}$ treatment paradigm), this solution was replaced with medium containing both compounds. This was followed by another $15 \mathrm{~min}$ (or $5 \mathrm{~min}$ ) treatment with medium containing only the blocking agent, after which the normal medium was reintroduced to the slice chamber, and perfusion was resumed. These procedures have been shown not to induce phase shifts by themselves. Therefore, the times-of-peak for drug-treated slices were compared with the mean time-of-peak for untreated slices [zeitgeber time (ZT) $6.0 \pm 0.3, n=3$, where ZT0 is the time of lights-on in the animal colony] to determine the amount of phase shift induced by the treatment. ANOVAs and Student's $t$ tests were used, where appropriate, to test for significant differences between the means, with significance set at $p<0.05$. Chemicals used in the study were (+)-8-hydroxy-dipropylaminotetralin $\mathrm{HBr}$ [(+)DPAT], tetrodotoxin (TTX), 5-hydroxytryptamine (5-HT), bicuculline methiodide, L-glutamate, NMDA, AMPA, and kainate (Research Biochemicals, Natick, MA; Sigma).

Optic chiasm stimulation. Optic chiasm stimulation (OCS) was performed as described previously (Prosser, 1998a). Briefly, a bipolar, bluntcut, insulated tungsten electrode was positioned in the optic chiasm ventrolateral to the SCN. Voltage $(10 \mathrm{~Hz}, 10 \mathrm{~V}, 3 \mathrm{msec}$ duration) was applied for $15 \mathrm{~min}$ to determine the effect of stimulation alone. When combined with drug application, stimulation was applied first for $5 \mathrm{~min}$, then in combination with the drug for $10 \mathrm{~min}$, followed by a $5 \mathrm{~min}$ period of stimulation alone.

Multiunit activity recordings. Multiunit activity (MUA) recordings were used to determine the acute effects of experimental compounds on SCN neuronal activity. For these, a single $76 \mu \mathrm{m}$ diameter blunt-cut, Tefloncoated metal electrode ( $90 \%$ platinum $/ 10 \%$ iridium) was used as described previously (Prosser, 1998a). The electrode was first placed in the optic chiasm to determine the level of background electrical noise, and then it was moved to the SCN and lowered 50-100 $\mu \mathrm{m}$ into the slice. A threshold for counting electrical events (neuronal activity) was set to at least twice the level of background noise. Neuronal activity, expressed as the number of threshold crossings per second, was monitored continuously using a DataWave data collection and analysis system. After the MUA recording stabilized, drugs were rapidly perfused into the brain slice chamber $(40 \mathrm{ml} / \mathrm{hr}$; chamber volume, $3 \mathrm{ml})$ so that a complete exchange of the medium within the slice chamber occurred within 5 min. For each compound tested, the drug was applied for 15-30 min, followed by at least $30 \mathrm{~min}$ of perfusion with the normal medium. All drugs were applied during the first day in vitro, between ZT4 and ZT11. Although we have found MUA recordings provide a consistent and reliable record of acute changes in neuronal activity, we are unable to obtain reliable long-term (24-48 hr) recordings using MUA (Prosser, 1998a) and therefore do not use this technique for phase-shifting experiments.

\section{RESULTS}

\section{5-HTergic phase advances at ZT6}

Consistent with previous reports (Medanic and Gillette, 1992; Shibata et al., 1992b; Prosser et al., 1993), 5-HT (10 $\mu \mathrm{M})$ and (+)DPAT $(10 \mu \mathrm{M})$ induced robust phase advances when bathapplied to SCN slices for $1 \mathrm{hr}$ at ZT6 (Fig. 1). Similar phase
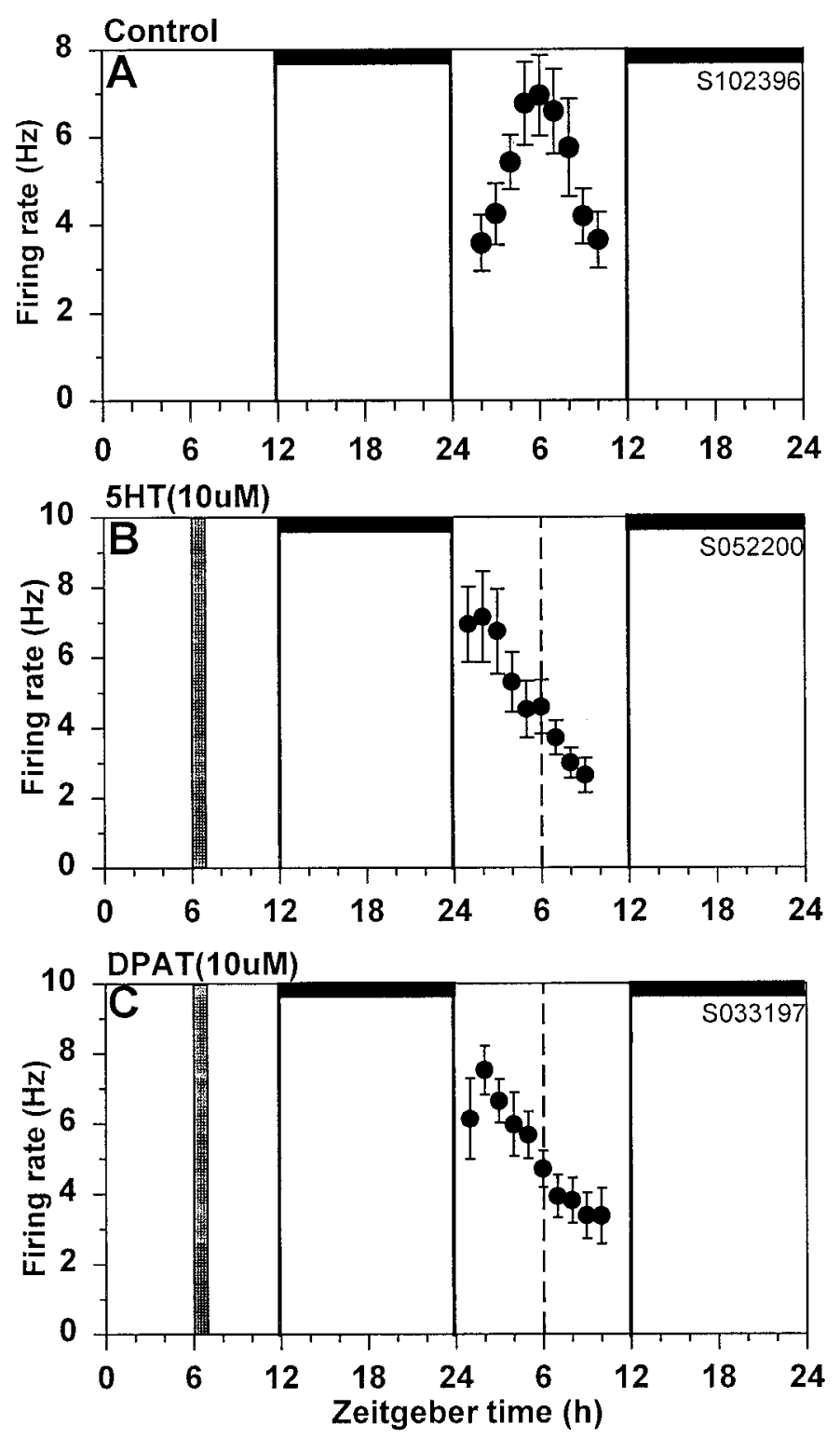

Figure 1. Serotonergic phase advances of the SCN neuronal activity rhythm. Shown are the $2 \mathrm{hr}$ means \pm SEM of SCN neuronal activity obtained in a control experiment $(A)$, after treatment with $10 \mu \mathrm{M} 5$-HT $(B)$, and after treatment with $(+)$ DPAT $(10 \mu \mathrm{M})(C)$. Neuronal activity peaked near ZT6 in the control experiment, whereas the peak in neuronal activity occurred at ZT2 after both the 5-HT and $(+)$ DPAT treatment. Thus, both 5-HT and (+)DPAT phase-advanced the neuronal activity rhythm by $4 \mathrm{hr}$. Horizontal bars, Time of lights-off in the animal colony; vertical bar, time of drug treatment; dotted line, mean time-of-peak in control experiments. 


\begin{tabular}{|c|c|c|c|}
\hline Treatment & Number & $\begin{array}{l}\text { Length of } \\
\text { treatment }\end{array}$ & Phase shift ${ }^{a}$ \\
\hline 5-HT $(10 \mu \mathrm{M})$ & 3 & $1 \mathrm{hr}$ & $4.3 \pm 0.2^{*}$ \\
\hline$(+) \operatorname{DPAT}(10 \mu \mathrm{M})^{b}$ & 3 & $1 \mathrm{hr}$ & $3.7 \pm 0.5^{*}$ \\
\hline$(+) \operatorname{DPAT}(10 \mu \mathrm{M})$ & 2 & $10 \mathrm{~min}$ & $4.0 \pm 0.0^{*}$ \\
\hline Glutamate $(10 \mathrm{~mm})$ & 2 & $1 \mathrm{hr}$ & $0.0 \pm 0.0$ \\
\hline AMPA $(10 \mu \mathrm{M})$ & 2 & $1 \mathrm{hr}$ & $0.8 \pm 0.4$ \\
\hline NMDA $(100 \mu \mathrm{M})$ & 2 & $1 \mathrm{hr}$ & $0.8 \pm 0.4$ \\
\hline Kainate $(100 \mu \mathrm{M})$ & 2 & $1 \mathrm{hr}$ & $0.5 \pm 0.0$ \\
\hline Optic chiasm stimulation & 3 & $15 \mathrm{~min}$ & $-0.2 \pm 0.2$ \\
\hline$(+) \operatorname{DPAT}(10 \mu \mathrm{M})+$ glutamate $(10 \mu \mathrm{M}-1 \mathrm{mM})$ & 2 & $1 \mathrm{hr}$ & $2.8 \pm 0.4^{*}$ \\
\hline$(+)$ DPAT $(10 \mu \mathrm{M})+$ glutamate $(10 \mathrm{~mm})$ & 3 & $1 \mathrm{hr}$ & $2.2 \pm 0.2^{*}$ \\
\hline$[(+) \operatorname{DPAT}(10 \mu \mathrm{M})+$ glutamate $(10 \mathrm{mM})] \times 3^{c}$ & 2 & $1 \mathrm{hr}$ & $0.3 \pm 0.4$ \\
\hline$[(+) \operatorname{DPAT}(10 \mu \mathrm{M})+$ glutamate $(10 \mathrm{mM})+\mathrm{TTX}(1 \mu \mathrm{M})] \times 3^{c}$ & 3 & $1 \mathrm{hr}$ & $3.2 \pm 0.1^{*}$ \\
\hline 5-HT $(10 \mu \mathrm{M})+$ AMPA $(10 \mu \mathrm{M})$ & 3 & $1 \mathrm{hr}$ & $0.3 \pm 0.2$ \\
\hline$(+)$ DPAT $(10 \mu \mathrm{M})+$ AMPA $(10 \mu \mathrm{M})$ & 3 & $1 \mathrm{hr}$ & $0.3 \pm 0.2$ \\
\hline$(+)$ DPAT $(10 \mu \mathrm{M})+$ AMPA $(10 \mu \mathrm{M})+$ TTX $(1 \mu \mathrm{M})$ & 3 & $1 \mathrm{hr}$ & $3.0 \pm 0.4^{*}$ \\
\hline$(+) \operatorname{DPAT}(10 \mu \mathrm{M})+$ NMDA $(10-100 \mathrm{~mm})$ & 4 & $1 \mathrm{hr}$ & $3.1 \pm 0.3^{*}$ \\
\hline$(+) \operatorname{DPAT}(10 \mu \mathrm{M})+$ NMDA $(100 \mu \mathrm{M})+\operatorname{AMPA}(0.1 \mu \mathrm{M})$ & 2 & $1 \mathrm{hr}$ & $3.1 \pm 0.2 *$ \\
\hline$[(+) \operatorname{DPAT}(10 \mu \mathrm{M})+\mathrm{NMDA}(10 \mu \mathrm{M})] \times 3^{c}$ & 2 & $1 \mathrm{hr}$ & $4.0 \pm 0.7^{*}$ \\
\hline$(+)$ DPAT $(10 \mu \mathrm{M})+$ NMDA $(100 \mu \mathrm{M})$ & 3 & $10 \mathrm{~min}$ & $0.1 \pm 0.1$ \\
\hline$(+) \operatorname{DPAT}(10 \mu \mathrm{M})+\mathrm{NMDA}(100 \mu \mathrm{M})+\mathrm{TTX}(1 \mu \mathrm{M})$ & 3 & $10 \mathrm{~min}$ & $3.3 \pm 0.5^{*}$ \\
\hline$(+)$ DPAT $(10 \mu \mathrm{M})+$ bicuculline $(30 \mu \mathrm{M})$ & 3 & $10 \mathrm{~min}$ & $3.9 \pm 0.1^{*}$ \\
\hline$(+) \operatorname{DPAT}(10 \mu \mathrm{M})+$ NMDA $(100 \mu \mathrm{M})+$ bicuculline $(30 \mu \mathrm{M})$ & 3 & $10 \mathrm{~min}$ & $3.8 \pm 0.1^{*}$ \\
\hline$(+)$ DPAT $(10 \mu \mathrm{M})+$ kainate $(10-100 \mu \mathrm{M})$ & 4 & $1 \mathrm{hr}$ & $3.4 \pm 0.3^{*}$ \\
\hline$[(+)$ DPAT $(10 \mu \mathrm{M})+$ kainate $(100 \mu \mathrm{M})] \times 3^{c}$ & 2 & $1 \mathrm{hr}$ & $3.3 \pm 0.4^{*}$ \\
\hline$(+)$ DPAT $(10 \mu \mathrm{M})+$ kainate $(100 \mu \mathrm{M})$ & 2 & $10 \mathrm{~min}$ & $3.5 \pm 0.0$ \\
\hline$(+)$ DPAT $(10 \mu \mathrm{M})+$ optic chiasm stimulation & 3 & $10 \mathrm{~min}$ & $0.8 \pm 0.2$ \\
\hline$(+) \operatorname{DPAT}(10 \mu \mathrm{M})+$ optic chiasm stimulation + bicuculline & 3 & $10 \mathrm{~min}$ & $3.17 \pm 0.2^{*}$ \\
\hline
\end{tabular}

${ }^{a}$ Phase shifts calculated by comparing the times-of-peak in drug-treated versus control slices with the mean time-of-peak in control slices of ZT $6.0 \pm 0.3(n=3)$.

${ }^{b}$ Data from Prosser (1998b).

$c$ " $\times 3$ " refers to three applications during the $1 \mathrm{hr}$ treatment period. For details, see Materials and Methods.

$* p<0.05$ versus control.

advances were also seen after $10 \mathrm{~min}$ bath-applications of $(+)$ DPAT (Table 1). Conversely, neither glutamate nor any of its agonists (AMPA, NMDA, and kainate) altered the phase of the neuronal activity rhythm when applied at ZT6 (Table 1). All glutamatergic compounds were tested at concentrations that were either known to affect SCN activity during the day (Shibata et al., 1992a; Flett and Colwell, 1999) or shown previously to induce phase shifts during the night (Ding et al., 1994; Shibata et al., 1994; Forrest and Prosser, 2000) (our unpublished data). These data are summarized in Table 1.

\section{Glutamatergic inhibition of 5-HTergic phase shifts}

Although it did not induce phase shifts when applied alone at ZT6, AMPA (10 $\mu \mathrm{M})$ completely abolished the phase advances induced by both 5-HT and (+)DPAT under $1 \mathrm{hr}$ static bath conditions (Fig. 2). AMPA inhibition of (+)DPAT-induced phase shifts was dose-dependent, with an $\mathrm{ED}_{50} \sim 1 \mu \mathrm{M}$ (Fig. 3). Glutamate, when reapplied three times during the course of the $1 \mathrm{hr}$ treatment period (see Materials and Methods), also completely blocked (+)DPAT-induced phase advances. As with AMPA, this inhibition was dose-dependent, although much higher concentrations of glutamate were needed to block $(+)$ DPAT-induced phase shifts (Fig. 3).
NMDA and kainate, at concentrations up to $100 \mu \mathrm{M}$, were completely ineffective at blocking phase advances induced by $1 \mathrm{hr}$ (+)DPAT bath application at ZT6 (Table 1). These results were surprising because NMDA and kainate receptors are abundant in the SCN (van den Pol et al., 1994, 1996; Mikkelsen et al., 1993); NMDA and kainate increase SCN neuronal activity and intracellular $\mathrm{Ca}^{2+}$ levels (Shibata et al., 1992a; Dudek et al., 1993; Haak, 1999); and NMDA phase-shifts the SCN pacemaker when applied during the night (Ebling et al., 1991; Ding et al., 1994, 1997; Mintz and Albers, 1997; Mintz et al., 1999; Forrest and Prosser, 2000). However, in some systems, functional activation of NMDA receptors requires concurrent AMPA receptorinduced depolarization (van den Pol et al., 1996; Dingledine et al., 1999). Therefore, we tested the ability of a combined application of AMPA $(0.1 \mu \mathrm{M})$ with $100 \mu \mathrm{M}$ NMDA. This combination still did not block (+)DPAT-induced phase advances (Table 1).

Further investigation into the effects of AMPA and NMDA on SCN neuronal activity revealed that the excitation induced by NMDA dampened rapidly, so that activity often returned to near baseline levels within 15 min of its initial application. In contrast, the excitatory response to AMPA generally lasted much longer (Fig. 4). Thus, we speculated that NMDA might be more effective 

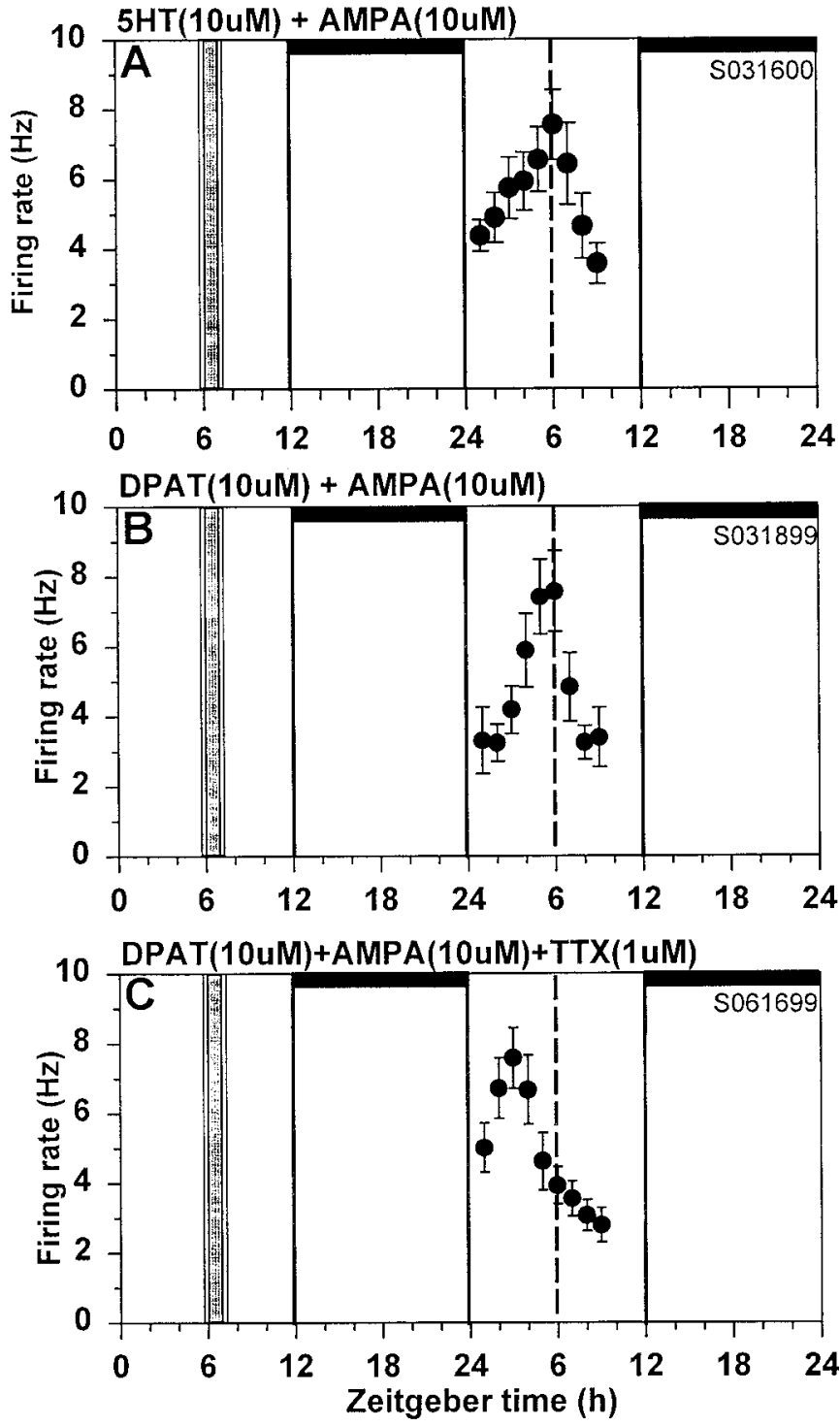

Figure 2. AMPA blocks serotonergic phase advances of the SCN neuronal activity rhythm. $A$, Coapplication of AMPA $(10 \mu \mathrm{M})$ blocks the 5-HT-induced phase advance. $B$, Coapplication of AMPA $(10 \mu \mathrm{M}) \mathrm{com}$ pletely abolished the $(+)$ DPAT-induced phase advance. $C$, TTX $(1 \mu \mathrm{M})$ prevents the inhibition by AMPA, thus restoring the (+)DPAT-induced phase advance. See Figure 1 legend for details.

when coapplied with $(+)$ DPAT for a shorter length of time. In fact, NMDA completely blocked the phase advances induced by 10 min bath application of (+)DPAT (NMDA applied alone for 5 min before and after (+)DPAT-NMDA treatment). Similar inhibition still was not seen when kainate was coapplied with (+)DPAT for $10 \mathrm{~min}$. (Table 1).

\section{Optic chiasm stimulation inhibits serotonergic phase shifts}

Next, we investigated whether stimulation of endogenous glutamate release could block serotonergic phase advances. To test this, we applied electrical stimulation to the optic chiasm, which should stimulate release of glutamate from retinal terminals in the SCN (Liou et al., 1986). This treatment had no effect on the rhythm of SCN neuronal activity when applied alone at ZT6, but it inhibited phase advances induced by $10 \mathrm{~min}$ bath application of (+)DPAT (Fig. 5, Table 1).
Inhibition of DPAT-Induced Phase Shifts

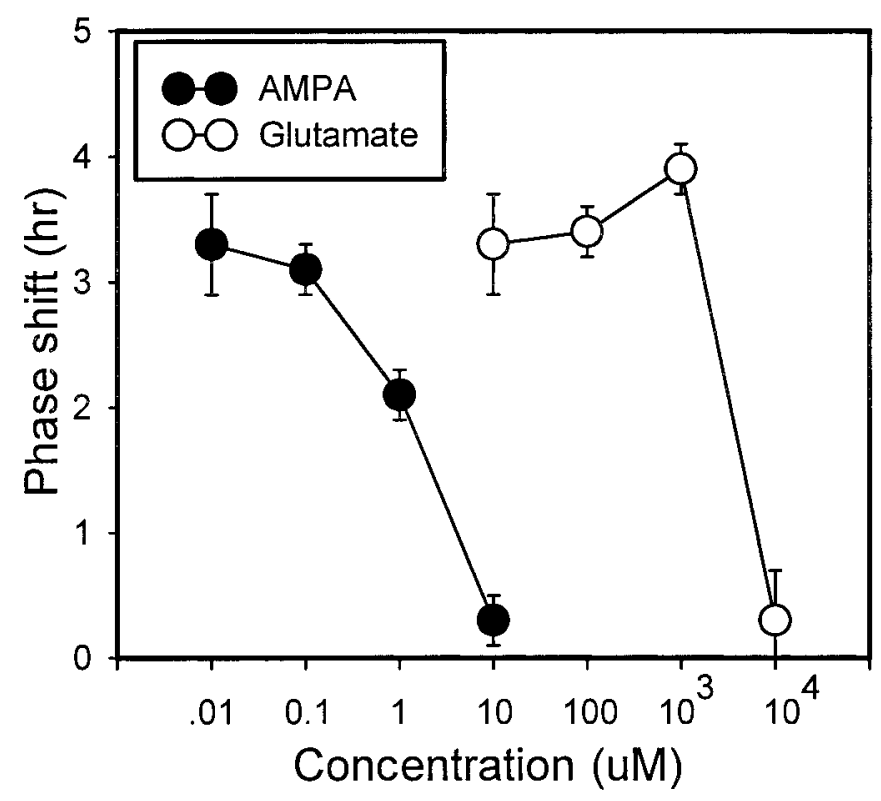

Figure 3. Dose dependence of glutamatergic inhibition. Shown are the mean phase advances $( \pm$ SEM) induced by $(+)$ DPAT application alone and in the presence of varying concentrations of AMPA (filled circles) and glutamate (open circles). Complete inhibition occurred with $10 \mu \mathrm{M}$ AMPA and $10 \mathrm{~mm}$ glutamate (when glutamate is reapplied 3 times during the $1 \mathrm{hr}$ treatment period). The $\mathrm{ED}_{50}$ for AMPA is near $1 \mu \mathrm{M}$ and for glutamate is near $5 \mathrm{~mm}$.

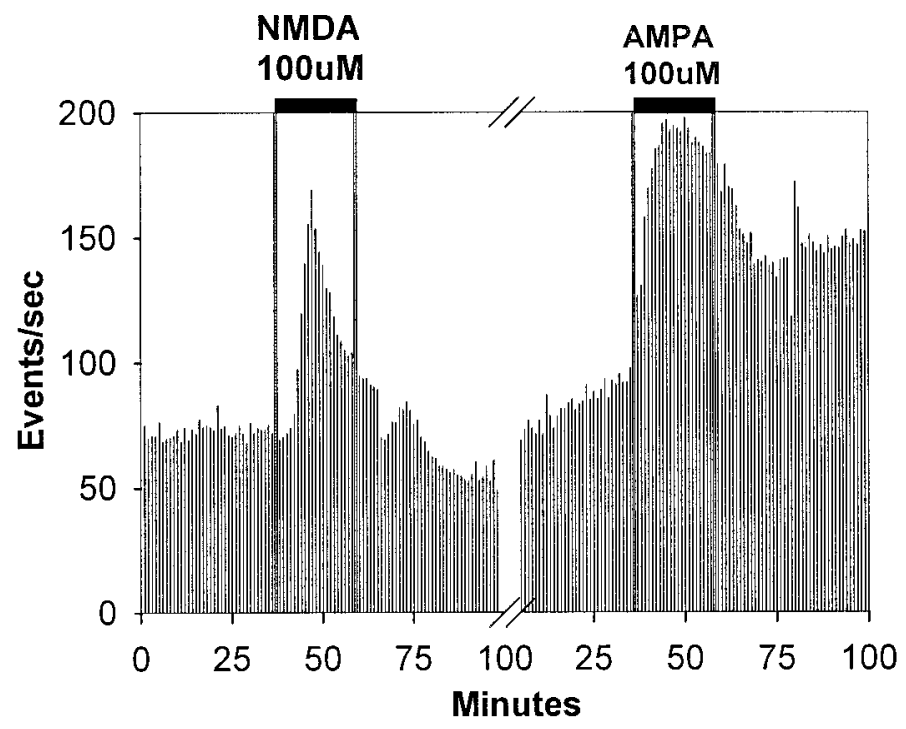

Figure 4. Multiunit activity recordings from the SCN showing acute effects of NMDA and AMPA on SCN neuronal activity. Perfusion application of NMDA to the $\mathrm{SCN}$ slice induced a large increase in activity that rapidly returned to near baseline levels. Conversely, neuronal activity remained high throughout the period of AMPA application.

\section{Glutamatergic inhibition is blocked by TTX and bicuculline}

Finally, we investigated whether the glutamatergic inhibition involves direct or indirect interactions with $5-\mathrm{HT}$, that is, whether the 5-HT and glutamate agonists act on the same cells. To initially address this question, we applied TTX in conjunction with glutamate, AMPA, or NMDA under the experimental conditions in 

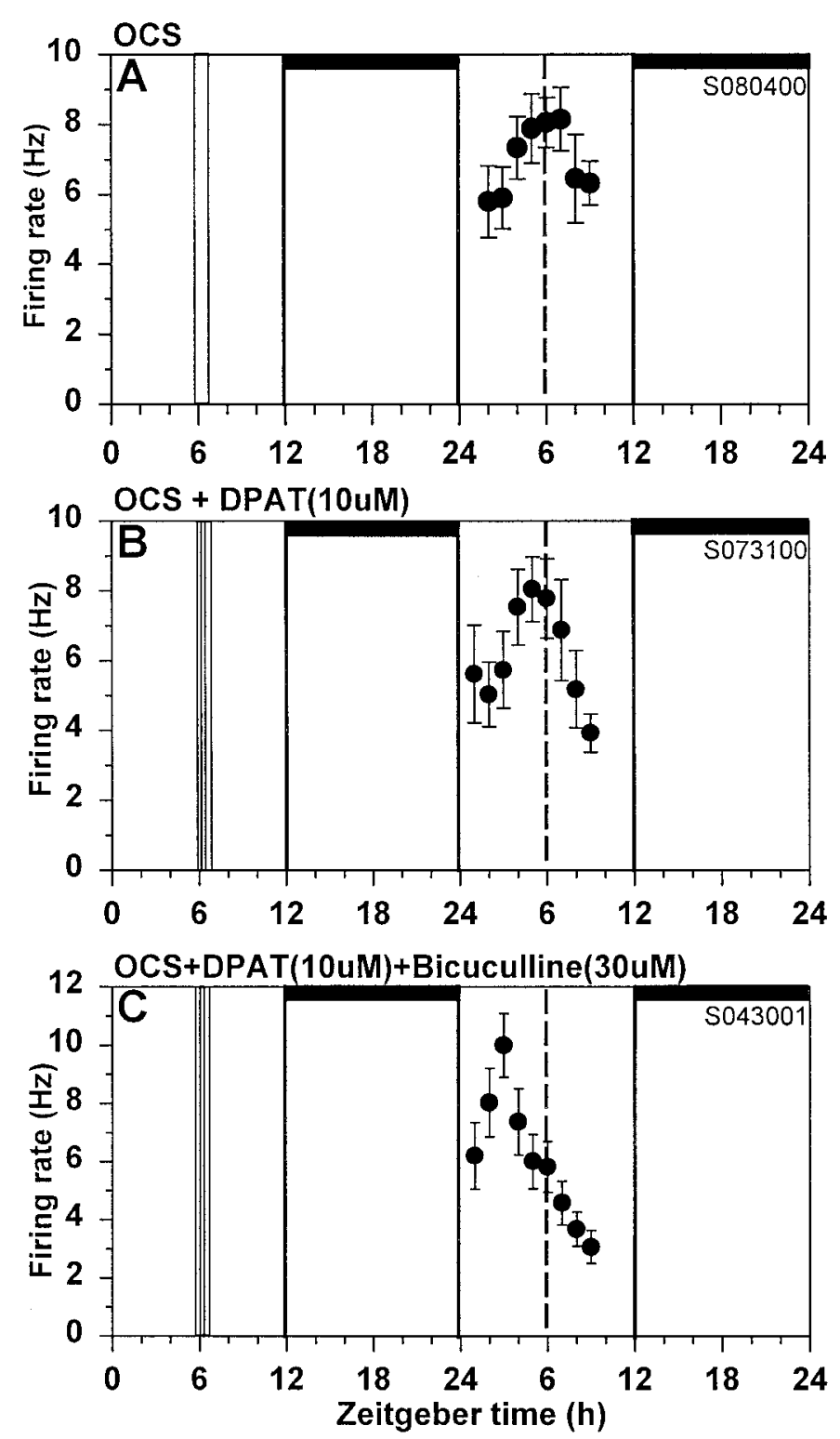

Figure 5. Optic chiasm stimulation inhibits serotonergic phase advances. $A$, Electrical stimulation of the optic chiasm at ZT6 for $15 \mathrm{~min}$ did not shift the rhythm of SCN neuronal activity. $B$, Optic chiasm stimulation inhibited the phase advance induced by $10 \mathrm{~min}$ application of (+)DPAT, so the peak in neuronal activity occurred near ZT6. $C$, Bicuculline coapplied with OCS reinstates the (+)DPAT-induced phase advance. See Figure 1 legend for details.

which each compound had been found to block (+)DPATinduced phase advances. In all cases, TTX prevented the glutamatergic inhibition, so that the (+)DPAT-induced phase advance was reinstated (Figs. 2, 6; Table 1). Application of TTX alone at ZT6 does not induce phase shifts (Bergeron et al., 1999), and TTX does not block serotonergic phase shifts at ZT6 (Prosser et al., 1992).

These results suggest that the inhibition by glutamate and its agonists requires $\mathrm{Na}^{+}$-dependent action potentials to be formed. If this is the case, then the inhibition by glutamate may involve SCN interneurons. To address this possibility, we tested whether the glutamatergic inhibition was sensitive to blockade of GABA receptors. We have previously shown that the selective $\mathrm{GABA}_{\mathrm{A}}$ antagonist, bicuculline, does not induce phase shifts when applied

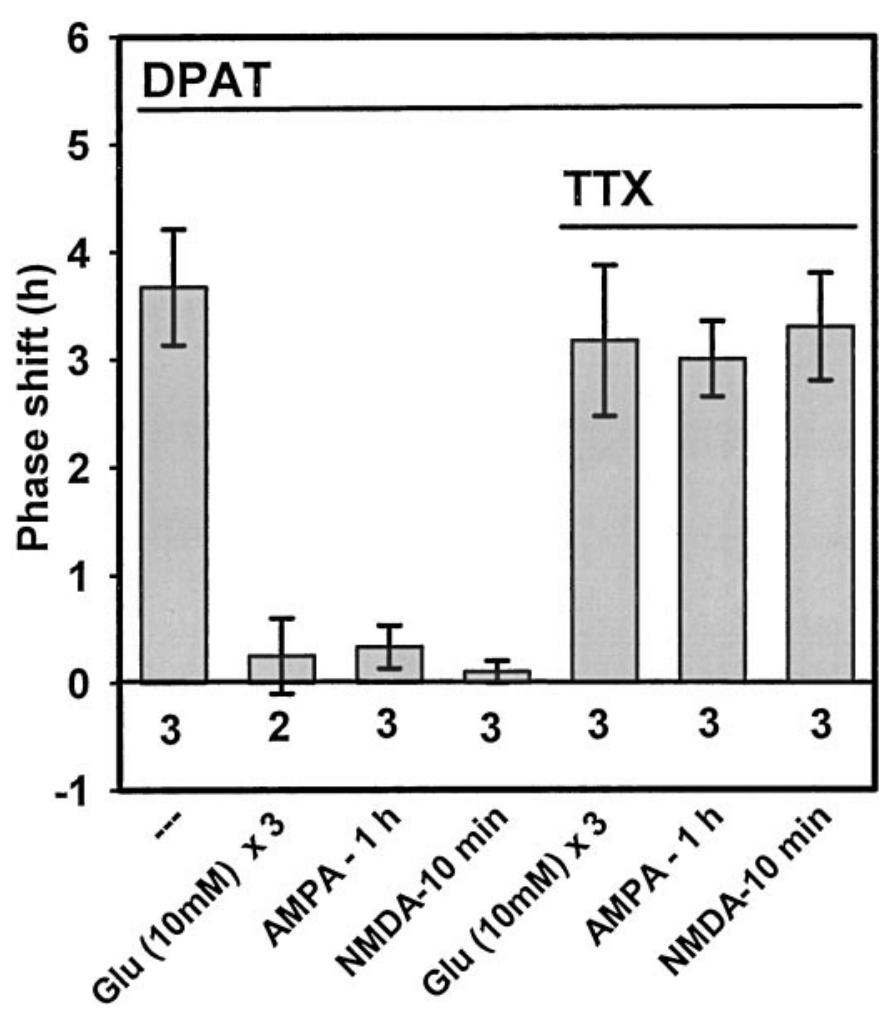

Figure 6. Glutamate inhibition of $(+)$ DPAT-induced phase advances is blocked by TTX. Shown are the mean phase advances $( \pm$ SEM) induced by $(+)$ DPAT alone or in the presence of glutamate agonists with and without TTX present. The inhibition by glutamate, AMPA, and NMDA are all prevented when TTX is coapplied. Numbers under the bars indicate the number of experiments.

to the SCN in vitro at ZT6 (Bergeron et al., 1999). In these experiments we first tested whether bicuculline affects phase advances by $(+)$ DPAT. As seen in Figure 7 , bicuculline $(30 \mu \mathrm{M})$ did not block $(+)$ DPAT-induced phase shifts, but it did block the inhibition by NMDA (Fig. 7). To further investigate this effect, we tested whether bicuculline also prevents OCS inhibition of $(+)$ DPAT-induced phase shifts. As shown in Figure 5, coapplication of bicuculline with OCS and (+)DPAT reinstates the full 5-HTergic phase advance. These data are summarized in Table 1.

\section{DISCUSSION}

These data are the first to reveal glutamatergic inhibition of serotonergic phase shifts in vitro, demonstrating that this inhibition takes place in or near the SCN. As such, they extend the body of research showing a pattern of inhibitory interactions between photic and nonphotic stimuli. Furthermore, the results suggest that this inhibition may also occur in response to electrical stimulation of the optic chiasm.

In our experiments, we were able to inhibit the serotonergic phase shifts through stimulation of either NMDA or AMPA receptors, but not through stimulation of kainate receptors. This is similar to the results of studies investigating photic phase shifts, in which stimulation of both NMDA and AMPA receptors can mimic light-induced phase shifts. The ability of kainate to induce photic phase shifts has not, to our knowledge, been reported. Although we cannot completely rule out involvement of kainate receptors in the inhibitory actions seen here, none of the treatment regimens we tried were effective with kainate. 


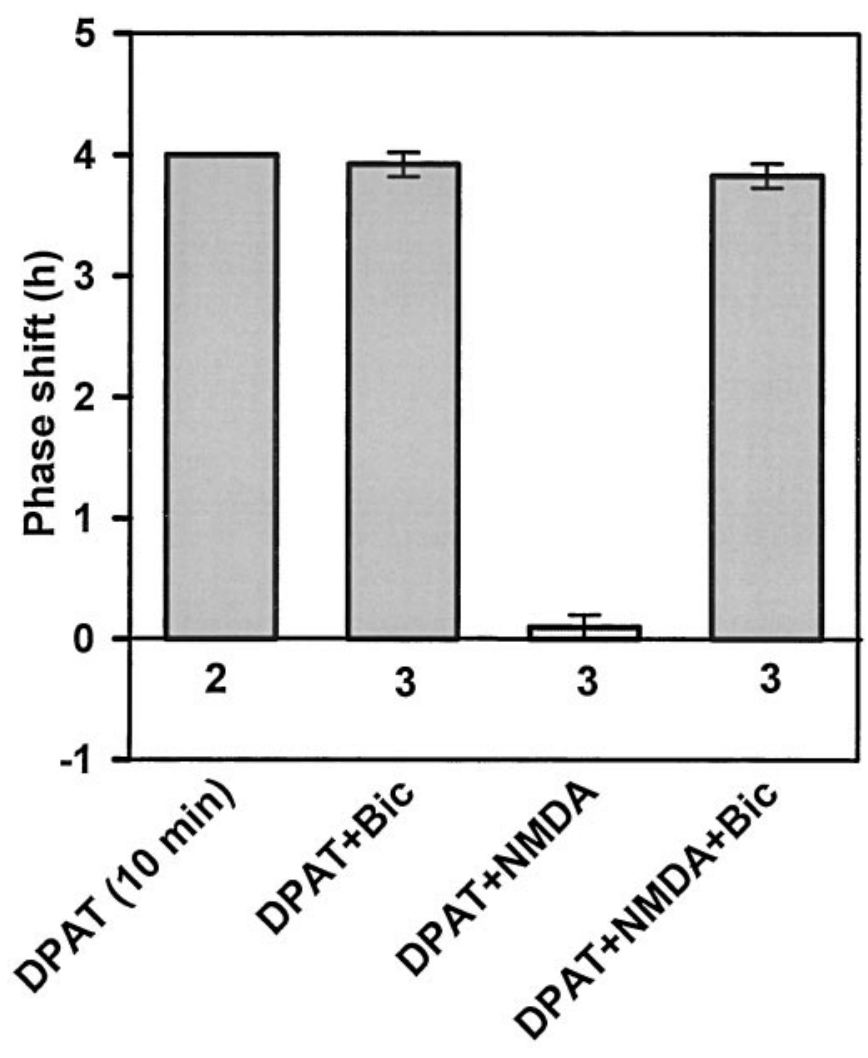

Figure 7. Bicuculline (Bic) prevents glutamatergic inhibition of $(+)$ DPAT-induced phase shifts. Shown are the mean phase advances ( \pm SEM) induced by $(+)$ DPAT in the presence of NMDA and/or bicuculline. Bicuculline did not affect the $(+)$ DPAT-induced phase advance but did prevent the inhibition by NMDA. See Figure 6 legend for details.

A large number of in vivo studies have shown that 5-HT can inhibit photic phase shifts. The evidence strongly supports a combination of presynaptic and postsynaptic sites of 5-HT action. Presynaptically, 5-HT stimulates $5-\mathrm{HT}_{1 \mathrm{~B}}$ receptors that are located on retinal ganglion cell terminals in the SCN to inhibit light-induced glutamate release (Pickard and Rea, 1997b; Pickard et al., 1999). 5-HT also appears to act postsynaptically on either $5-\mathrm{HT}_{1 \mathrm{~A}}$ or $5-\mathrm{HT}_{7}$ receptors to block the phase-shifting actions of glutamate (Rea et al., 1994, 1995; Moriya et al., 1996; Weber et al., 1998; Smith et al., 2001). The results of this study demonstrate the reverse situation, i.e., that glutamate can inhibit serotonergic phase shifts. These results are consistent with recent in vivo experiments showing that light can inhibit daytime phase advances induced by DPAT perfusion into the SCN (Ehlen et al., 2001). Interestingly, Challet et al. (1998) found that phase shifts induced by DPAT injection in the intergeniculate leaflet were blocked by light, whereas phase shifts induced by SCN injection of DPAT were not.

The mutual inhibition between light-glutamate and 5-HT is similar to that previously shown for light-glutamate and NPY (Biello et al., 1994, 1997; Yannielli and Harrington, 2000). Thus, it may be that in the SCN there is a general pattern of mutual inhibition between photic and nonphotic stimuli. The frequency with which interactions between phase-shifting stimuli have been observed raises interesting questions concerning how animals normally synchronize their daily rhythms to the environment. Results such as these lend support to the idea that synchronization involves a complex integration of multiple stimuli rather than an overriding reliance on a single environmental cue such as light. The interactions observed between phase-shifting stimuli acting within the SCN are also quite interesting because they now include two examples of a neurotransmitter (glutamate) modulating the actions of neuromodulators (5-HT and NPY). Results such as these raise the general issue of whether a clear functional distinction can be drawn between classical "neurotransmitters" and "neuromodulators".

Previous studies have demonstrated that light can inhibit activity-arousal-induced phase shifts (Mrosovsky, 1991; Biello and Mrosovsky, 1995; Antle and Mistlberger, 2000; Grossman et al., 2000). It has yet to be resolved to what extent these phase shifts occur through 5-HT, NPY, or other neurotransmitters (Biello et al., 1994; Wickland and Turek, 1994; Biello, 1995; Bobrzynska et al., 1996; Antle et al., 1998; Mistlberger and Antle, 1998). It is likely that diverse neural substrates underlie these phase shifts and that their specific roles vary somewhat between different species and between the types of arousal being investigated. The data presented here show that photic inhibition of activity-induced phase shifts in rats could involve glutamate acting within the SCN to inhibit postsynaptic actions of 5-HT. Whether or not this occurs in vivo and whether this underlies some aspects of photic inhibition of activity-induced phase shifts remains to be determined.

The results presented here are especially interesting in light of a recent study showing that sleep deprivation, which induces robust daytime phase advances, increases 5-HT release in the SCN by $160 \%$, and further, that light inhibits the sleep deprivation-induced phase shifts but not the release of 5-HT in the SCN (Grossman et al., 2000). Although the inhibition by light could involve neural substrates outside the $\mathrm{SCN}$, our results indicate that the inability of light to suppress 5-HT release in the SCN does not exclude the SCN from being the site of light inhibition of the phase shifts. Light could be inhibiting the phase shifts by blocking postsynaptic actions of 5-HT in the SCN. This interpretation is also consistent with data showing that light inhibits DPAT-induced phase shifts in vivo (Ehlen et al., 2001).

Previous work has demonstrated that serotonergic phase shifts are not blocked by TTX (Prosser et al., 1992), suggesting that 5-HT may act directly on clock cells. Likewise, in vivo phase shifts in response to intra-SCN injections of glutamate are not blocked by TTX, indicating that glutamate may also act directly on clock cells to phase-shift the circadian pacemaker (Mintz et al., 1999). However, the results presented here show that the inhibition of serotonergic phase shifts by glutamate is blocked by TTX. This suggests that the inhibition by glutamate requires $\mathrm{Na}^{+}$-dependent action potentials and is indirect. This could mean that interneurons within the SCN are required to convey the glutamate signal to 5-HT-stimulated cells. If that is the case, then it is likely that the intervening neurons use GABA as their neurotransmitter, because of its ubiquitous presence in SCN cells (van den Pol et al., 1996). Our results showing that bicuculline prevents the glutamatergic inhibition are consistent with this hypothesis. To further test this hypothesis, one would like to determine whether GABA blocks 5-HT-induced phase shifts. This experiment will be difficult, however, because we have shown that activation of both $\mathrm{GABA}_{\mathrm{A}}$ and $\mathrm{GABA}_{\mathrm{B}}$ receptors in the $\mathrm{SCN}$ induces phase advances in the subjective day at the same circadian phases that 5-HT induces phase shifts (Biggs and Prosser, 1998; Bergeron et al., 1999).

Finally, our experiments show that electrical stimulation of the optic chiasm also blocks serotonergic phase shifts. One concern 
with this procedure is that the electrical stimulation may induce nonspecific release of neurotransmitters in the SCN slice. There are two reasons why we do not think that is occurring here. First, general depolarization would be expected to induce release of GABA, the most abundant neurotransmitter in the SCN (van den Pol and Dudek, 1993). However, GABA induces robust phase advances in the SCN at ZT6 (Biggs and Prosser, 1998; Bergeron et al., 1999), whereas optic chiasm stimulation does not. Second, we find that the electrical stimulation parameters used in these experiments induce phase shifts at night that mimic the phaseshifting effects of glutamate (T. Braden, V. McMillan, and R. A. Prosser, unpublished data). Together, we interpret these data as supporting the conclusion that optic chiasm stimulation blocks DPAT-induced phase shifts through inducing the release of endogenous glutamate.

In summary, this study presents evidence that glutamate, acting through both AMPA and NMDA receptors, can block the phasemodulating effects of serotonin in the SCN in vitro. This inhibition is prevented by coapplication of either TTX or the GABA antagonist, bicuculline, suggesting there is an indirect interaction between glutamate and serotonin with respect to phase-shifting the SCN pacemaker. These results are consistent with previous work showing mutually inhibitory interactions between photic and nonphotic stimuli in modulating the phase of the mammalian circadian pacemaker.

\section{REFERENCES}

Akiyama M, Kouzu Y, Takahashi S, Wakamatsu H, Moriya T, Maetani M, Watanabe S, Tei H, Sakaki Y, Shibata S (1999) Inhibition of lightor glutamate-induced mPer2 expression represses the phase shifts into the mouse circadian locomotor and suprachiasmatic firing rhythms. J Neurosci 19:1115-1121.

Antle MC, Mistlberger RE (2000) Circadian clock resetting by sleep deprivation without exercise in the Syrian hamster. J Neurosci 20:9326-9332.

Antle MC, Marchant EG, Niel L, Mistlberger RE (1998) Serotonin antagonists do not attenuate activity-induced phase shifts of circadian rhythms in the Syrian hamster. Brain Res 813:139-149.

Bergeron HE, Danielson B, Biggs KR, Prosser RA (1999) TTX blocks baclofen-induced phase shifts of the mammalian circadian pacemaker in vitro. Brain Res 841:193-196.

Biello SM (1995) Enhanced photic phase shifting after treatment with antiserum to neuropeptide Y. Brain Res 673:25-29.

Biello SM, Mrosovsky N (1995) Blocking the phase-shifting effect of neuropeptide Y with light. Proc R Soc Lond B Biol Sci 259:179-187.

Biello SM, Janik D, Mrosovsky N (1994) Neuropeptide Y and behaviorally induced phase shifts. Neuroscience 62:273-279.

Biello SM, Golombek DA, Harrington ME (1997) Neuropeptide Y and glutamate block each other's phase shifts in the suprachiasmatic nucleus in vitro. Neuroscience 77:1049-1057.

Biggs KR, Prosser RA (1998) $\mathrm{GABA}_{\mathrm{B}}$ receptor stimulation phase-shifts the mammalian circadian clock in vitro. Brain Res 807:250-254.

Bobrzynska KJ, Vrang N, Mrosovsky N (1996) Persistence of nonphotic phase shifts in hamsters after serotonin depletion in the suprachiasmatic nucleus. Brain Res 741:205-214.

Cassone VM, Chesworth M, Armstrong SM (1985) Entrainment of rat circadian rhythms by daily injections of melatonin: synchronization in constant light and dependence upon the suprachiasmatic nuclei. Soc Neurosci Abstr 11:1140.

Challet E, Scarbrough K, Penev PD, Turek FW (1998) Roles of suprachiasmatic nuclei and intergeniculate leaflets in mediating the phaseshifting effects of a serotonergic agonist and their photic modulation during subjective day. J Biol Rhythms 13:410-421.

Ding JM, Chen D, Weber ET, Faiman LE, Rea MA, Gillette MU (1994) Resetting the biological clock: mediation of nocturnal circadian shifts by glutamate and NO. Science 266:1713-1717.

Ding JM, Faiman LE, Hurst WJ, Kuriashkina LR, Gillette MU (1997) Resetting the biological clock: mediation of nocturnal CREB phosphorylation via light, glutamate, and nitric oxide. J Neurosci 17:667-675.

Ding JM, Buchanan GF, Tischkau SA, Chen D, Kuriashkina L, Faiman LE, Alster JM, McPherson PS, Campbell KP, Gillette MU (1998) A neuronal ryanodine receptor mediates light-induced phase delays of the circadian clock. Nature 394:381-384.

Dingledine R, Borges K, Bowie D, Traynelis SF (1999) The glutamate receptor ion channels. Pharmacol Rev 51:7-61.
Dudek FE, Kim YI, Bouskila Y (1993) Electrophysiology of the suprachiasmatic nucleus: synaptic transmission, membrane properties, and neuronal synchronization. J Biol Rhythms 8: S33-S37.

Ebling FJP, Maywood ES, Staley K, Humby T, Hancock DC, Waters CM, Evan GI, Hastings MH (1991) The role of $N$-methyl-D-aspartate-type glutamatergic neurotransmission in the photic induction of immediateearly gene expression in the suprachiasmatic nuclei of the Syrian hamster. J Neuroendocrinol 3:641-652.

Edgar DM, Miller JD, Prosser RA, Dean RR, Dement WC (1993) Serotonin and the mammalian circadian system. II. Phase-shifting rat behavioral rhythms with serotonergic agonists. J Biol Rhythms 8:17-31.

Ehlen JC, Grossman GH, Glass JD (2001) In vivo resetting of the hamster circadian clock by $5-\mathrm{HT}_{7}$ receptors in the suprachiasmatic nucleus. J Neurosci 21:5351-5357.

Field MD, Maywood ES, O'Brien JA, Weaver DR, Reppert SM, Hastings MH (2000) Analysis of clock proteins in mouse SCN demonstrates phylogenetic divergence of the circadian clockwork and resetting mechanisms. Neuron 25:437-447.

Flett J, Colwell CS (1999) Serotonin modulation of calcium transients in cells in the suprachiasmatic nucleus. J Biol Rhythms 14:354-363.

Forrest JB, Prosser RA (2000) Interactions between glutamate and serotonin agonists in phase-shifting the mammalian circadian clock in vitro at night. Soc Neurosci Abstr 26:189.

Francois-Bellan A-M, Deprez P, Becquet D (1999) Light-induced variations in AP-1 binding activity and composition in the rat suprachiasmatic nucleus. J Neurochem 72:841-847.

Gillette MU, McArthur AJ (1996) Circadian actions of melatonin at the suprachiasmatic nucleus. Behav Brain Res 73:135-139.

Golombek DA, Biello SM, Rendon RA, Harrington ME (1996) Neuropeptide $\mathrm{Y}$ phase shifts the circadian clock in vitro via a Y2 receptor. NeuroReport 7:1315-1319.

Grossman GH, Mistlberger RE, Antle MC, Ehlen JC, Glass JD (2000) Sleep deprivation stimulates serotonin release in the suprachiasmatic nucleus. NeuroReport 11:1929-1932.

Haak LL (1999) Metabotropic glutamate receptor modulation of glutamate responses in the suprachiasmatic nucleus. J Neurophysiol $81: 1308-1317$.

Hamada T, Liou SY, Fukushima T, Maruyama T, Watanabe S, Mikoshiba $\mathrm{K}$, Ishida $\mathrm{N}$ (1999) The role of inositol trisphosphate-induced $\mathrm{Ca}^{2+}$ release from $\mathrm{IP}_{3}$-receptor in the rat suprachiasmatic nucleus on circadian entrainment mechanism. Neurosci Lett 263:125-128.

Hatton GI, Doran AD, Salm AK, Tweedle CD (1980) Brain slice preparation: hypothalamus. Brain Res Bull 5:405-414.

Hertz L, Dringen R, Schousboe A, Robinson SR (1999) Astrocytes: glutamate producers for neurons. J Neurosci Res 57:417-428.

Liou SY, Shibata S, Iwasaki K, Ueki S (1986) Optic nerve stimulationinduced increase of release of ${ }^{3} \mathrm{H}$-glutamate and ${ }^{3} \mathrm{H}$-aspartate but not ${ }^{3} \mathrm{H}-\mathrm{GABA}$ from the suprachiasmatic nucleus in slices of rat hypothalamus. Brain Res Bull 16:527-531.

Medanic M, Gillette MU (1992) Serotonin regulates the phase of the rat suprachiasmatic circadian pacemaker in vitro only during the subjective day. J Physiol (Lond) 450:629-642.

Mikkelsen JD, Larsen PJ, Ebling FJP (1993) Distribution of $N$-methyl D-aspartate (NMDA) receptor mRNAs in the rat suprachiasmatic nucleus. Brain Res 632:329-333.

Mintz EM, Albers HE (1997) Microinjection of NMDA into the SCN region mimics the phase shifting effect of light in hamsters. Brain Res 758:245-249.

Mintz EM, Marvel CL, Gillespie CF, Price KM, Albers HE (1999) Activation of NMDA receptors in the suprachiasmatic nucleus produces light-like phase shifts of the circadian clock in vivo. J Neurosci 19:5124-5130.

Mistlberger RE, Antle MC (1998) Behavioral inhibition of light-induced circadian phase resetting is phase and serotonin dependent. Brain Res 786:31-38.

Moore RY (1995) Organization of the mammalian circadian system. Ciba Found Symp 183:88-106.

Moriya T, Yamanouchi S, Fukushima T, Shimazoe T, Shibata S, Watanabe $S$ (1996) Involvement of $5-\mathrm{HT}_{1 \mathrm{~A}}$ receptor mechanisms in the inhibitory effects of methamphetamine on photic responses in the rodent suprachiasmatic nucleus. Brain Res 740:261-267.

Mrosovsky N (1991) Double-pulse experiments with nonphotic and photic phase-shifting stimuli. J Biol Rhythms 6:167-179.

Mrosovsky N (1995) A non-photic gateway to the circadian clock of hamsters. Ciba Found Symp 183:154-174.

Obrietan K, Impey S, Smith D, Athos J, Storm DR (1999) Circadian regulation of cAMP response element-mediated gene expression in the suprachiasmatic nuclei. J Biol Chem 274:17748-17756.

Pickard GE, Rea MA (1997a) Serotonergic innervation of the hypothalamic suprachiasmatic nucleus and photic regulation of circadian rhythms. Biol Cell 89:513-523.

Pickard GE, Rea MA (1997b) TFMPP, a 5HT 1 receptor agonist, inhibits light-induced phase shifts of the circadian activity rhythm and c-Fos expression in the mouse suprachiasmatic nucleus. Neurosci Lett 231:95-98. 
Pickard GE, Weber ET, Scott PA, Riberdy AF, Rea MA (1996) 5-HT HB $_{1 \mathrm{~B}}$ receptor agonists inhibit light-induced phase shifts of behavioral circadian rhythms and expression of the immediate-early gene $c$-fos in the suprachiasmatic nucleus. J Neurosci 16:8208-8220.

Pickard GE, Smith BN, Belenky M, Rea MA, Dudek FE, Sollars PJ (1999) 5-HT $1 \mathrm{~B}$ receptor-mediated presynaptic inhibition of retinal input to the suprachiasmatic nucleus. J Neurosci 19:4034-4045.

Prosser RA (1998a) In vitro circadian rhythms of the mammalian suprachiasmatic nuclei: comparison of multi-unit and single-unit neuronal activity recordings. J Biol Rhythms 13:30-38.

Prosser RA (1998b) Neuropeptide Y blocks serotonergic phase shifts of the suprachiasmatic circadian clock in vitro. Brain Res 808:31-41.

Prosser RA, Gillette MU (1989) The mammalian circadian clock in the suprachiasmatic nuclei is reset in vitro by cAMP. J Neurosci 9:1073-1081.

Prosser RA, Heller HC, Miller JD (1992) Serotonergic phase-shifts of the mammalian circadian clock: effects of tetrodotoxin and high $\mathrm{Mg}^{2+}$. Brain Res 573:336-340.

Prosser RA, Dean RR, Edgar DM, Heller HC, Miller JD (1993) Serotonin and the mammalian circadian system. I. In vitro phase shifts by serotonergic agonists and antagonists. J Biol Rhythms 8:1-16.

Ralph MR, Mrosovsky N (1992) Behavioral inhibition of circadian responses to light. J Biol Rhythms 7:353-359.

Rea MA, Glass JD, Colwell CS (1994) Serotonin modulates photic responses in the hamster suprachiasmatic nuclei. J Neurosci 14:3635-3642.

Rea MA, Barrera J, Glass JD, Gannon RL (1995) Serotonergic potentiation of photic phase shifts of the circadian activity rhythm. NeuroReport 6:1289-1292.

Shibata S, Tominaga K, Hamada T, Watanabe S (1992a) Excitatory effect of $N$-methyl-D-aspartate and kainate receptor on the 2-deoxyglucose uptake in the rat suprachiasmatic nucleus in vitro. Neurosci Lett 139:83-86.

Shibata S, Tsuneyoshi A, Hamada T, Tominaga K, Watanabe S (1992b) Phase-resetting effect of 8-OH-DPAT, a serotonin ${ }_{1 \mathrm{~A}}$ receptor agonist, on the circadian rhythm of firing rate in the rat suprachiasmatic nuclei in vitro. Brain Res 582:353-356.

Shibata S, Watanabe A, Hamada T, Ono M, Watanabe S (1994) $\mathrm{N}$-methyl-D-aspartate induces phase shifts in circadian rhythm of neuronal activity of rat SCN in vitro. Am J Physiol 267:R360-R364.
Shinohara K, Honma S, Katsuno Y, Abe H, Honma K (1995) Two distinct oscillators in the rat suprachiasmatic nucleus in vitro. Proc Natl Acad Sci USA 92:7396-7400.

Smith BN, Sollars PJ, Dudek FE, Pickard GE (2001) Serotonergic modulation of retinal input to the mouse suprachiasmatic nucleus mediated by $5-\mathrm{HT}_{1 \mathrm{~B}}$ and $5-\mathrm{HT}_{7}$ receptors. J Biol Rhythms 16:25-38.

Smith RD, Inouye S-IT, Turek FW (1989) Central administration of muscimol phase-shifts the mammalian circadian clock. J Comp Physiol 164:805-814.

Takahashi JS, Zatz M (1982) Regulation of circadian rhythmicity. Science 217:1104-1111.

Tominaga K, Shibata S, Ueki S, Watanabe S (1992) Effects of 5-HT receptor agonists on the circadian rhythm of wheel-running activity in hamsters. Eur J Pharmacol 214:79-84.

van den Pol AN, Dudek FE (1993) Cellular communication in the circadian clock, the suprachiasmatic nucleus. Neuroscience 56:793-811. van den Pol AN, Hermans-Borgmeyer I, Hofer M, Ghosh P, Heinemann S (1994) Ionotropic glutamate-receptor gene expression in hypothalamus: localization of AMPA, kainate, and NMDA receptor RNA with in situ hybridization. J Comp Neurol 343:428-444.

van den Pol AN, Strecker GJ, Dudek FE (1996) Excitatory and inhibitory amino acids and synaptic transmission in the suprachiasmatic nucleus. In: Hypothalamic integration of circadian rhythms (Buijs RM, Kalsbeek A, Romijn HJ, Pennartz CMA, Mirmiran M, eds), pp 41-56. Amsterdam: Elsevier.

Weber ET, Gannon RL, Rea MA (1998) Local administration of serotonin agonists blocks light-induced phase advances of the circadian activity rhythm in the hamster. J Biol Rhythms 13:209-218.

Wickland C, Turek FW (1994) Lesions of the thalamic intergeniculate leaflet block activity-induced phase shifts in the circadian activity rhythm of golden hamster. Brain Res 660:293-300.

Yamazaki S, Numano R, Abe M, Hida A, Takahashi R-I, Ueda M, Block GD, Sakaki Y, Menaker M, Tei H (2000) Resetting central and peripheral circadian oscillators in transgenic rats. Science 288:682-685.

Yannielli PC, Harrington ME (2000) Neuropeptide Y applied in vitro can block the phase shifts induced by light in vivo. NeuroReport 11:1587-1591.

Yudkoff M, Nissim I, Daikhin Y, Lin Z-P, Nelson D, Pleasure D, Erecinska M (1994) Brain glutamate metabolism: neuronalastroglial relationships. Dev Neurosci 15:343-350. 